\title{
Climate Treaties and Backstop Technologies
}

\author{
Scott Barrett
}

\author{
CESIFO WORKING PAPER No. 3003 \\ CATEGORY 10: ENERGY AND Climate ECONOMICS \\ MARCH 2010
}

Presented at CeSifo Area Conference on Energy \& Climate Economics, October 2009

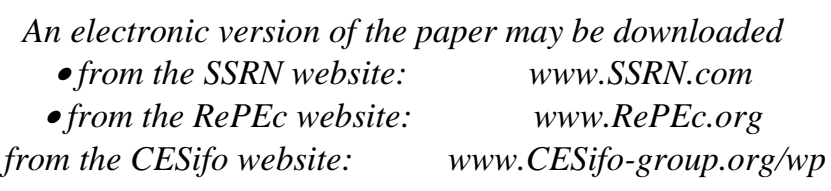




\title{
Climate Treaties and Backstop Technologies
}

\begin{abstract}
In this paper I examine the design of climate treaties when there exist two kinds of technology, a conventional abatement technology with (linearly) increasing marginal costs and a backstop technology ("air capture") with high but constant marginal costs. I focus on situations in which countries can gain collectively by using both technologies. I show that, under some circumstances, countries will be better off negotiating treaties that are not costeffective. When countries prefer to negotiate self-enforcing agreements that are costeffective, the availability of the backstop technology causes cooperation in abatement to increase significantly.
\end{abstract}

JEL-Code: Q54.

\author{
Scott Barrett \\ School of International and Public Affairs and \\ Earth Institute \\ Columbia University \\ 420 West 118th Street, Room 1427 \\ USA - New York, NY 10027 \\ sb3116@columbia.edu
}

29 March 2010

This paper was given as a keynote lecture at the CESifo area conference on Energy \& Climate Economics, Munich, Germany, 16-17 October, 2009. I am grateful to the participants of this conference for their comments on the paper, and to Michael Hoel for inviting me to give the paper. 


\section{Introduction}

International environmental agreements are second best institutions. They can improve on unilateralism, but usually fall short of sustaining full cooperation. Climate change is a particularly difficult challenge. Because the marginal costs of reducing greenhouse gas emissions increase sharply, at least beyond some point, the incentives to free ride are substantial-and impossible for an international environmental agreement to overcome using the usual mechanism of reciprocity.

This is why other strategies need to be considered. A few papers have shown that, under certain circumstances, a technology-oriented strategy can help. Heal (1994) shows that cooperation can be facilitated when abatement costs are interdependent. Golombek and Hoel (2004) show that R\&D spillovers may cause new technologies to be diffused globally-producing a kind of negative leakage. I have shown that R\&D directed at technologies exhibiting strong network externalities can transform the problem of deterring free riding (Barrett 2006). Finally, Hoel and de Zeeuw (2009) show that cooperation in $R \& D$ can increase global abatement by reducing the costs of adopting a new technology. In this paper I explore a different perspective. This is to consider two technologies that lower atmospheric concentrations of greenhouse gases in very different ways - a conventional abatement technology that reduces emissions at increasing marginal cost and a novel technology that reduces atmospheric concentrations directly by removing $\mathrm{CO}_{2}$ from the air. This novel technology, known generically as "air capture," has a constant but very high marginal cost. 
There are a number of ways to remove $\mathrm{CO}_{2}$ from the air (Barrett 2009). Several approaches exploit the process of photosynthesis. Credits for afforestation and reforestation are already incorporated in the Kyoto Protocol (avoided deforestation, the subject of ongoing negotiations, would limit additions to atmospheric concentrations). A related approach is to use biomass as a fuel for electricity generation, and then to capture and store the $\mathrm{CO}_{2}$ from combustion, resulting in negative net emissions. Another idea is to fertilize iron-limited regions of the oceans, to stimulate the growth of phytoplankton, which, if they sink to the deep ocean, will cause the surface waters to extract $\mathrm{CO}_{2}$ from the air to restore chemical balance. Unfortunately, the effects of all these biological approaches are difficult to verify, limited in scale, and prone to having worrying side effects. ${ }^{1}$

In this paper I consider "industrial” air capture. This involves a technology that brings air into contact with a chemical "sorbent" (an alkaline liquid). The sorbent absorbs $\mathrm{CO}_{2}$ in the air, and the industrial process then separates out the $\mathrm{CO}_{2}$, recycles the sorbent, and stores the captured $\mathrm{CO}_{2}$ in geologic deposits, just like $\mathrm{CO}_{2}$ removed from a power plant's stack gases. Industrial air capture has several desirable features (Sarewitz and Nelson 2008). It would be decoupled from our energy systems, and could be located near geologic sites for long-term carbon storage and away from population areas, where land has a low opportunity cost. It could also be scaled to any level. Conceivably, every other

\footnotetext{
${ }^{1}$ Ocean fertilization is perhaps the most worrying of these proposals. In 2007, the 84 parties to the London Convention/Protocol endorsed a "statement of concern" about ocean fertilization, and urged parties "to use the utmost caution when considering proposals for large-scale ocean fertilization operations." (See OSPAR Decision 2007/02 on Storage of Carbon Dioxide Streams in Geological Formations, June 2007.)
} 
aspect of the global economy could remain unaltered, and this technology be used to sustain virtually any desired reduction in atmospheric levels of carbon. From the perspective of emission reductions, industrial air capture is a true "backstop technology."

Industrial air capture is expensive. Estimates of marginal cost range from \$100$\$ 200 / \mathrm{tCO}_{2}$. Industrial air capture is much more costly than the alternatives for reducing emissions, including power plant $\mathrm{CO}_{2}$ capture and storage. Its marginal costs also exceed current estimates of the social cost of carbon, which range from about $\$ 7-\$ 85 / \mathrm{tCO}_{2}$. However, the marginal cost of industrial air capture is lower than estimates of the cost of meeting a $2^{\circ} \mathrm{C}$ temperature change target by means of abatement technology by around $2100 .{ }^{2}$ In the future, use of industrial air capture may be collectively optimal.

Though costly, industrial air capture has offsetting advantages. Because it acts directly on reducing concentrations, industrial air capture offers more options for the timing of investment as compared with emission reductions (Pielke 2007). Even if the intention were not to deploy this technology, it may pay for us to develop it as a hedge against future climate change risks, given its unique ability to be scaled to reduce concentrations directly. Finally, unlike emission reductions, industrial air capture could be deployed by a single country, or by a "coalition of the willing."

In this paper my focus is on the effect of air capture on the design and efficiency of international treaty arrangements. How should climate treaties be designed when

\footnotetext{
${ }^{2}$ All of these estimates can be found in Barrett (2009).
} 
countries have the option not only to abate their emissions but also to employ industrial air capture as a backstop technology?

\section{An abatement-only treaty}

Begin by considering the abatement decisions of countries in the absence of a multilateral agreement. Let $q_{i}$ denote country $i$ 's abatement and let $Q$ denote aggregate abatement; with $N$ countries, $Q=\sum_{i=1}^{N} q_{i}$. Finally, let country $i$ 's payoff be given by $\pi_{i}=b Q-c q_{i}^{2} / 2$. If countries choose their abatement levels independently, there exists a unique Nash equilibrium in which every country $i$ plays $q_{i}=b / c$. If countries were able to cooperate fully, each would play $q_{i}=b N / c$.

A treaty can be represented as the equilibrium of a stage game, with countries deciding whether to participate in stage 1 , with parties choosing their abatement levels collectively in stage 2 , and with non-parties choosing their abatement levels independently in stage 3 . As is usual, we solve the game backwards.

Since the equilibrium of the earlier abatement game, $q_{i}=b / c$, is in dominant strategies, it must also be the equilibrium of the stage 3 game. Letting $k_{q}$ denote the number of signatories to the abatement-only agreement, collective maximization by signatories implies that each signatory must play $q_{s}=b k_{q} / c$ in stage 2 . Finally, letting $\pi_{s}$ and $\pi_{n}$ denote the payoff to a signatory and non-signatory, respectively, a Nash equilibrium of 
the stage 1 game is a participation level $k_{q}^{*}$ satisfying $\pi_{s}\left(k_{q}^{*}\right) \geq \pi_{n}\left(k_{q}^{*}-1\right)$ and $\pi_{n}\left(k_{q}^{*}\right) \geq \pi_{s}\left(k_{q}^{*}+1\right)$. Upon substitution, it is easy to show that the equilibrium participation level is $k_{q}^{*}=3$ for $N \geq 3$. Plainly, a treaty consisting of just 3 countries will not make much of a difference when $N$ is large. The agreement increases aggregate abatement from $b N / c$ to just $b(N+6) / c$, while full cooperation requires that abatement increase to $b N^{2} / c$.

Though this result emerges from a special model, it can be shown to be qualitatively robust (Barrett 2005). The result need not be taken literally to mean that only three countries will cooperate. If the assumption about credibility is weakened just a little, then, in a repeated game context, it can be shown that the level of participation can be increased all the way to $N$. The problem is that, as the participation level increases, the abatement level of each participant must fall in order for the agreement to be selfenforcing (Barrett 2002). A more general interpretation of this result is that a second best abatement treaty is likely to improve little on non-cooperation and fall far short of full cooperation. Though the model is implausibly simple, its prediction is consistent with the experience of negotiations thus far. The Kyoto Protocol may have caused some countries to reduce their emissions a little, but it has certainly not sustained full cooperation, and the Copenhagen Accord promises to do no better.

\section{An air-capture-only treaty}


Assume now that countries can only mitigate climate change by means of air capture. Let $z_{i}$ denote country $i$ 's level of air capture, and assume $z_{i} \in[0, \bar{z}]$. I noted previously that air capture can be scaled to virtually any level. However, in this paper I assume that air capture and abatement are comparable in their effects - both yielding equal and constant marginal benefits. It is thus reasonable to think of air capture as being bounded in this static model to a level perhaps not much different than a year's emissions.

Let $Z$ denote the aggregate reduction in greenhouse gas concentrations (relative to business as usual) due to air capture; with $N$ countries, $Z=\sum_{i=1}^{N} z_{i}$. Finally, let country $i$ 's payoff be given by $\pi_{i}=b Z-\gamma z_{i}$. If countries choose their air capture levels independently, and if $\gamma>b$, then there will exist a Nash equilibrium in which every country $i$ plays $z_{i}=0$. If $\gamma>b N$, then this equilibrium will also be first best. Let us assume, however, that $\gamma<b N$ (this, as noted previously, is a situation in which we might find ourselves in the future). Then the above Nash equilibrium will be inefficient.

Can a treaty help? Let us see. In stage 3 , non-signatories will plainly play $z_{n}=0$. In stage 2, signatories will play $z_{s}=\bar{z}$ if $b k_{z} \geq \gamma$ and $z_{s}=0$ otherwise, where $k_{z}$ denotes the number of parties to the air-capture-only treaty. Finally, in equilibrium, the number of signatories will be $k_{z}^{*}$ with $\gamma / b+1 \geq k_{z}^{*} \geq \gamma / b$.

Note that, while the equilibrium number of signatories to an air capture protocol can be large, when this number is large the overall gains to cooperation will be small. As with an 
abatement-only treaty, an air-capture-only treaty can improve little on the noncooperative outcome (though, as we shall see, unlike an abatement-only treaty, an aircapture-only treaty may come close to sustaining full cooperation).

\section{A combined protocol}

I have so far modeled abatement and air capture as independent choices. But the equilibrium levels of marginal cost vary substantially as between the two agreements. In the equilibrium abatement protocol, marginal cost is $3 b$. In the equilibrium air capture protocol, marginal cost is $\gamma$. As explained previously, it is very likely that $\gamma>3 b$. This means that, if abatement and air capture are addressed in separate protocols, mitigation will not be cost-effective.

It seems more plausible to assume that cooperating countries would want to negotiate a single agreement, with the decisions to abate and carry out air capture being optimized jointly. How might such a treaty be designed?

Because marginal benefits are assumed to be constant, the first order conditions for both abatement and air capture will be unchanged as compared with the previous analyses. Non-signatories will play $q_{n}=b / c$ and $z_{n}=0$. Signatories will play $q_{s}=k_{+} b / c$, where $k_{+}$denotes the number of parties to the combined protocol; they will play $z_{s}=\bar{z}$ for $k_{+} \geq \gamma / b$ and $z_{s}=0$ for $k_{+}<\gamma / b$. Of course, the non-cooperative and full cooperative outcomes will also be unchanged as compared with the earlier analyses. 
While these conditions will remain unchanged, the treaty equilibria may be very different. So long as $\gamma>>3 b$, there will exist one treaty equilibrium in which parties to the agreement only abate their emissions. In this equilibrium, each of the $k_{q}^{*}=3$ signatories will undertake three times the abatement as each non-signatory, and each nonsignatory will undertake the same level of abatement as in the non-cooperative outcome. No country will undertake air capture in this equilibrium (again, assuming $\gamma>>3 b$ ).

If $b N>\gamma$ there may also exist a treaty equilibrium at $\gamma / b+1>k_{z}^{*}>\gamma / b$. However, we cannot be sure that an agreement comprising this number of parties will be self-enforcing. The reason is that, in a combined protocol, the countries investing in air capture must undertake abatement at the same marginal cost, and we know that such a high level of abatement cannot be sustained by an abatement-only agreement-the incentives to free ride are too great. For this second equilibrium to exist, therefore, the returns to air capture must be large enough to offset the returns lost by foregoing free riding.

For $\gamma / b+1>k_{z}^{*}>\gamma / b$ to be an equilibrium in a combined treaty we must have $\pi_{n}(k) \geq \pi_{s}(k+1)$ at $k_{z}^{*}$. That is, we require

$$
b\left[(N-k) \frac{b}{c}+k^{2} \frac{b}{c}+k \bar{z}\right]-\frac{c}{2}\left(\frac{b}{c}\right)^{2} \geq b\left[(N-k-1) \frac{b}{c}+(k+1)^{2} \frac{b}{c}+(k+1) \bar{z}\right]-\frac{c}{2}\left(\frac{b(k+1)}{c}\right)^{2}-\gamma \bar{z},
$$


which reduces to $b^{2} k(k-2)+(\gamma-b) 2 c \bar{z} \geq 0$. This condition will clearly be satisfied.

We also require $\pi_{s}(k) \geq \pi_{n}(k-1)$ at $k_{z}^{*}$ or

$$
b\left[(N-k) \frac{b}{c}+k^{2} \frac{b}{c}+k \bar{z}\right]-\frac{c}{2}\left(\frac{b k}{c}\right)^{2}-\gamma \bar{z} \geq b\left[(N-k+1) \frac{b}{c}+(k-1)^{2} \frac{b}{c}\right]-\frac{c}{2}\left(\frac{b}{c}\right)^{2},
$$

which reduces to

$$
-b^{2} k^{2}+2 b(c \bar{z}+2 b) k-\left(3 b^{2}+2 \gamma c \bar{z}\right) \geq 0 \text {. }
$$

This second condition may or may not be satisfied. It is more likely to be satisfied if $c$ and $\bar{z}$ are "large" and $\gamma$ is "small" (the effect of $b$ is ambiguous).

The value of $k$ that maximizes the LHS of (1) is $k=c \bar{z} / b+2$. Substituting this value into (1) yields

$$
(c \bar{z}+2 b)^{2}-\left(3 b^{2}+2 \gamma c \bar{z}\right) \geq 0 .
$$

This condition is necessary for an agreement with $k$ parties (where $k$ is the smallest integer greater than $\gamma / b)$ to be self-enforcing. Solving the quadratic in (1), this same value of $k$ must lie between $\underline{k}$ and $\bar{k}$, where 


$$
\underline{k}, \bar{k}=\left(\frac{c \bar{z}}{b}+2\right) \pm \frac{\sqrt{(c \bar{z}+2 b)^{2}-\left(3 b^{2}+2 \gamma c \bar{z}\right)}}{b}
$$

For a combined treaty comprising $k_{+}^{*}$ countries to be self-enforcing, with $k_{+}^{*}$ being equal to the smallest integer greater than $\gamma / b$, we must have $k_{+}^{*} \in[\underline{k}, \bar{k}]$.

Even though the model is very simple, I have been unable to obtain an analytical solution for the equilibrium, combined treaty. Table 1 presents simulations from which several conclusions follow:

1. An abatement-only treaty improves little over the non-cooperative outcome. The simulations thus confirm what we already knew.

2. The possibility of air capture can increase payoffs dramatically provided $\bar{z}$ is "large" or $c$ is "large." If $\bar{z}$ is "large," the trigger for air capture ( $k$ being larger than $\gamma / b)$ reduces concentrations dramatically, delivering a substantial benefit to every country. If $c$ is "large" very little abatement is done, with or without an abatement-only treaty, and air capture can therefore make a substantial difference to the overall level of mitigation.

3. As illustrated by Simulation I, a combined (and, therefore, cost-effective) protocol may not be self-enforcing. Put differently, an insistence on cost-effectiveness may cause air capture not to be used, even though every country would be better off if it were used in a separate treaty, part of a package of cost-ineffective mitigation arrangements. This result makes an important point: that cost-effectiveness may 
not be a feature of a second-best treaty arrangement; that a focus on costeffectiveness could actually reduce welfare all around.

4. Comparison of Simulations I and II reveals that a combined protocol is more likely to be self-enforcing if the capacity for air capture, $\bar{z}$, is "large." This, of course, is because the gains to adding air capture to an abatement treaty must be large enough to overcome the incentive to free ride in abatement.

5. As suggested by a comparison of Simulations I and III, a higher marginal abatement cost, $c$, also helps to make a combined treaty self-enforcing. The reason is that, when c is "large," little abatement will be undertaken even if countries cooperate at a high level $\left(k_{+}^{*}\right)$. The losses an individual country experiences by cooperating in abatement (at $k_{+}^{*} \gg k_{q}^{*}$ ) will therefore be small, meaning that the benefits to cooperating in air capture do not need to be as large to make a combined treaty self-enforcing.

6. Comparison of Simulations I and IV shows that a lower marginal cost of air capture, $\gamma$, has a similar effect. However, in this case the equilibrium participation level falls. The losses to cooperating in abatement are reduced, but so are the gains to adding air capture.

7. Finally, comparison of Simulations IV and V shows that a higher marginal benefit to mitigation, $b$, also lowers the participation level in a self-enforcing, combined treaty (this is because the trigger for air capture is $k \geq \gamma / b$ ). Ironically, a higher marginal benefit shrinks the payoff to combining air capture and abatement. 
In a combined treaty, air capture provides a vehicle for raising the participation level among countries that cooperate to reduce their emissions. However, this helps (in percentage terms) a lot only for Simulation IV, and in this case there is a wide gap (again, in percentage terms) between the aggregate payoff for a combined protocol and the full cooperative outcome.

I have so far emphasized the overall advantages and disadvantages of negotiating a combined treaty. What are the implications for individual countries? Table 2 summarizes the payoffs to individual countries for the simulations in Table 1. Two perspectives are important. The first is the perspective countries might take to negotiating a combined treaty after the abatement-only and air-capture-only treaties have been realized. The second is the perspective countries might take to combining treaties before any treaty has been developed. In the latter case, countries have a symmetric perspective on the decision to combine. In the former case, they do not.

Table 2 shows that, if the decision to negotiate separate or combined treaties is made in a preliminary stage, the perspective of every country will be identical, and the decision to negotiate separate treaties or a combined treaty will be unanimous. If the parameter values correspond to Simulation I, every country will prefer to negotiate separate treaties. They will eschew possibilities for cost-effectiveness. If the parameter values correspond to Simulations II-V, every country will prefer to negotiate a combined treaty in which abatement and air capture are cost-effective. 
If the decision of whether to combine treaties is made at a later stage, after countries have already negotiated separate abatement and air capture treaties, then countries may disagree. For Simulations II and III, non-signatories to the air-capture-only treaty will not want to negotiate a combined treaty, whether or not they are signatories to the abatementonly treaty (their payoffs would be expected to fall from over $\$ 600,000$ to just under $\$ 127,000)$. However, for both simulations, parties to the air-capture-only treaty prefer a combined treaty, and since the equilibrium number of parties will be the same for a combined treaty, we can be sure that a combined treaty will be sustained. 
TABLE 1

Simulations

\begin{tabular}{|c|c|c|c|c|c|c|}
\hline \multicolumn{2}{|c|}{ Simulation } & I & II & III & IV & $\mathrm{V}$ \\
\hline \multirow{4}{*}{ 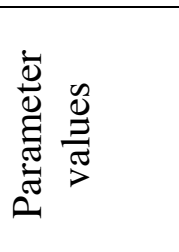 } & $b$ & 1 & 1 & 1 & 1 & 5 \\
\hline & $c$ & 1 & 1 & 1,000 & 1 & 1 \\
\hline & $\gamma$ & 79.5 & 79.5 & 79.5 & 19.5 & 19.5 \\
\hline & $\bar{z}$ & 10 & 7,500 & 10 & 10 & 10 \\
\hline \multirow{4}{*}{ 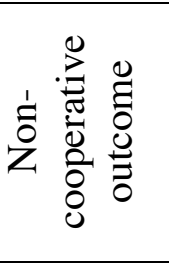 } & $q^{o}$ & 1 & 1 & 0.001 & 1 & 5 \\
\hline & $Q^{o}$ & 100 & 100 & 0.1 & 100 & 500 \\
\hline & $\pi^{o}$ & 99.5 & 99.5 & 0.1 & 99.5 & $2,487.5$ \\
\hline & $\Pi^{o}$ & 9,950 & 9,950 & 9.95 & 9,950 & 248,750 \\
\hline \multirow{5}{*}{ 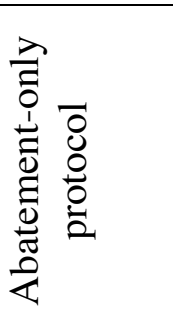 } & $q_{s}^{*}$ & 3 & 3 & 0.003 & 3 & 15 \\
\hline & $Q^{*}$ & 106 & 106 & 0.11 & 106 & 530 \\
\hline & $\pi_{n}^{*}$ & 105.5 & 105.5 & 0.11 & 105.5 & $2,637.5$ \\
\hline & $\pi_{s}^{*}$ & 101.5 & 101.5 & 0.10 & 101.5 & $2,537.5$ \\
\hline & $\Pi_{q}^{*}$ & 10,538 & 10,538 & 10.5 & 10,538 & 263,450 \\
\hline \multirow{5}{*}{ 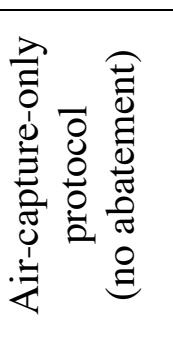 } & $k_{z}^{*}$ & 80 & 80 & 80 & 20 & 4 \\
\hline & $Z^{*}$ & 800 & 600,000 & 800 & 200 & 40 \\
\hline & $\pi_{n}^{*}$ & 800 & 600,000 & 800 & 200 & 200 \\
\hline & $\pi_{s}^{*}$ & 5 & 3,750 & 5 & 5 & 5 \\
\hline & $\Pi_{z}^{*}$ & 16,400 & $12,300,000$ & 16,400 & 16,100 & 19,220 \\
\hline \multirow{2}{*}{$\begin{array}{c}\text { Both } \\
\text { protocols }\end{array}$} & $Q^{*}+Z^{*}$ & 906 & 600,106 & 800.11 & 306 & 570 \\
\hline & $\Pi_{q}^{*}+\Pi_{z}^{*}$ & 26,938 & $12,310,538$ & 16,411 & 26,638 & 282,670 \\
\hline \multirow{6}{*}{ 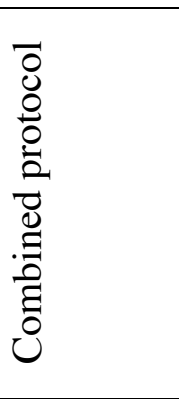 } & $k_{+}^{*}$ & -- & 80 & 80 & 20 & 4 \\
\hline & $q_{s}$ & -- & 80 & 0.08 & 20 & 20 \\
\hline & $Q^{*}+Z^{*}$ & -- & 606,420 & 806.42 & 680 & 600 \\
\hline & $\pi_{n}$ & -- & $606,419.5$ & 806.42 & 679.5 & $2,987.5$ \\
\hline & $\pi_{s}$ & -- & 6,970 & 8.22 & 480 & 2,800 \\
\hline & $\Pi_{+}^{*}$ & -- & $12,685,990$ & 16,786 & 63,960 & 298,000 \\
\hline \multirow{5}{*}{ 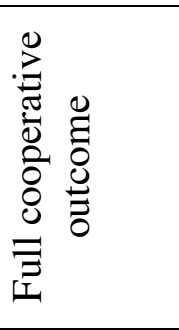 } & $q^{c}$ & 100 & 100 & 0.1 & 100 & 500 \\
\hline & $z^{c}$ & 10 & 7,500 & 10 & 10 & 10 \\
\hline & $Q^{c}+Z^{c}$ & 11,000 & 760,000 & 1,010 & 11,000 & 51,000 \\
\hline & $\pi^{c}$ & 5,205 & 158,750 & 210 & 5,805 & 129,805 \\
\hline & $\Pi^{c}$ & 520,500 & $15,875,000$ & 21,000 & 580,500 & $12,980,500$ \\
\hline
\end{tabular}


TABLE 2

Payoffs to individual countries

\begin{tabular}{|c|c|c|c|c|c|}
\hline Simulation & $\mathrm{I}$ & II & III & IV & $\mathrm{V}$ \\
\hline Non-cooperative outcome & 99.5 & 99.5 & 0.1 & 99.5 & $2,487.5$ \\
\hline $\begin{array}{l}\text { Signatory to abatement- } \\
\text { only treaty/Non-signatory } \\
\text { to air-capture-only treaty }\end{array}$ & 901.5 & $600,101.5$ & 800.10 & 301.5 & $2,737.5$ \\
\hline $\begin{array}{l}\text { Non-signatory to } \\
\text { abatement-only } \\
\text { treaty/Signatory to air- } \\
\text { capture-only treaty }\end{array}$ & 110.5 & $3,855.5$ & 5.11 & 110.5 & $2,642.5$ \\
\hline Signatory to both treaties & 106.5 & $3,851.5$ & 5.10 & 106.5 & $2,542.5$ \\
\hline $\begin{array}{l}\text { Non-signatory to both } \\
\text { treaties }\end{array}$ & 905.5 & $600,105.5$ & 800.11 & 305.5 & $2,837.5$ \\
\hline $\begin{array}{l}\text { Expected payoff with } \\
\text { separate treaties }\end{array}$ & 269.4 & $123,105.4$ & 164.1 & 266.4 & $2,826.7$ \\
\hline $\begin{array}{l}\text { Non-signatory to } \\
\text { combined treaty }\end{array}$ & 105.5 & $606,419.5$ & 806.42 & 679.5 & $2,987.5$ \\
\hline $\begin{array}{l}\text { Signatory to combined } \\
\text { treaty }\end{array}$ & 101.5 & 6,970 & 8.22 & 480 & 2,800 \\
\hline $\begin{array}{l}\text { Expected payoff with } \\
\text { combined treaty }\end{array}$ & 102.3 & $126,859.9$ & 167.9 & 639.6 & 2,980 \\
\hline Full cooperative outcome & 5,205 & 158,750 & 210 & 5,805 & 129,805 \\
\hline $\begin{array}{l}\text { Who would favor a } \\
\text { combined treaty? }\end{array}$ & No one & $\begin{array}{r}\text { Everyone } \\
\text { ex ante; } \\
\text { signatories } \\
\text { to air- } \\
\text { capture- } \\
\text { only treaty } \\
\text { or both } \\
\text { treaties ex } \\
\text { post. }\end{array}$ & $\begin{array}{r}\text { Everyone } \\
\text { ex ante; } \\
\text { signatories } \\
\text { to air- } \\
\text { capture- } \\
\text { only treaty } \\
\text { or both } \\
\text { treaties ex } \\
\text { post }\end{array}$ & Everyone & Everyone \\
\hline
\end{tabular}




\section{Air capture as a single project}

In the above analysis, I modeled air capture as a technology employed separately by different countries. However, and as noted in the introduction, air capture, unlike abatement, needn't be undertaken by a very large number of countries to have a big effect. Air capture can be deployed as a single project. The capacity for air capture at a particular location might be limited by the availability of geologic storage, but if $\mathrm{CO}_{2}$ were to be sequestered in silicate minerals, then this constraint would be eased (though at an additional cost).

Let us then consider a situation in which the amount of air capture undertaken overall is constrained, such that $\sum_{i=1}^{N} z_{i} \leq \bar{Z}$. Then, $k_{z}^{*}$ will again be the smallest integer greater than or equal to $\gamma / b$. However, the level of air capture undertaken for this $k$ will now be $\bar{Z}$ rather than $k_{z}^{*} \bar{z}$ (these values could, by chance, be equal). In this case, changes in the equilibrium participation level, $k_{z}^{*}$, will not change the amount of air capture undertaken in an air-capture-only treaty. In contrast to the previous analysis, the amount of air capture undertaken will be efficient. What will change, as participation changes, is the arrangement for cost sharing.

When air capture is undertaken as a single project, the variable $z_{i}$ is best thought of as a financing share. That is, for $k_{z} \geq \gamma / b$, each party to the treaty contributes an amount $\gamma z_{i}$ , with $\sum_{i} \gamma z_{i}=\gamma \bar{Z}$. In this model, countries are symmetric, and so the only plausible 
financing equilibrium is one in which parties share the total cost equally-this amount being $\gamma \bar{Z} / k_{z}^{*}$.

Using this formulation, for $k_{z}^{*} \in[\gamma / b, \gamma / b+1], \pi_{n}\left(k_{z}^{*}\right) \geq \pi_{s}\left(k_{z}^{*}\right)$ implies

$b\left[(N-k) \frac{b}{c}+k^{2} \frac{b}{c}+\bar{Z}\right]-\frac{c}{2}\left(\frac{b}{c}\right)^{2} \geq b\left[(N-k-1) \frac{b}{c}+(k+1)^{2} \frac{b}{c}+\bar{Z}\right]-\frac{c}{2}\left(\frac{b(k+1)}{c}\right)^{2}-\frac{\gamma \bar{Z}}{(k+1)}$

which reduces to $b^{2} k(k-2)(k+1)+2 c \gamma \bar{Z} \geq 0$. This condition will clearly be satisfied.

We also require $\pi_{s}\left(k_{z}^{*}\right) \geq \pi_{n}\left(k_{z}^{*}-1\right)$. Upon substituting, we get

$$
b\left[(N-k) \frac{b}{c}+k^{2} \frac{b}{c}+\bar{Z}\right]-\frac{c}{2}\left(\frac{b k}{c}\right)^{2}-\frac{\gamma \bar{Z}}{k} \geq b\left[(N-k+1) \frac{b}{c}+(k-1)^{2} \frac{b}{c}\right]-\frac{c}{2}\left(\frac{b}{c}\right)^{2}
$$

which reduces to

$$
-b^{2} k^{3}+4 b^{2} k^{2}+b(2 c \bar{Z}-3 b) k-2 c \gamma \bar{Z} \geq 0 .
$$

This second condition may or may not be satisfied.

Once again, I rely on simulations. The simulations shown in Table 3 correspond to the ones in Table 1 with the exception of air capture capacity. So that the results are broadly 
compatible, I assume that aggregate capacity is identical; that is, I take it that $\bar{Z}=\bar{z} N$. In comparing Tables 1 and 3, we can see that mitigation levels and payoffs are higher when air capture can be undertaken as a single project. In percentage terms, the difference is particularly noticeable for Simulations IV and V. In these cases, a relatively small number of countries deploy air capture in a self-enforcing treaty. For the simulations in Table 1, these countries undertake relatively little air capture, since the maximum amount per country is fixed. For the simulations in Table 3, these countries undertake a lot more, since only the total amount of air capture is fixed.

\section{Conclusions}

The literature on international environmental agreements has tended to put technology is a "black box." However, an emerging literature shows that technologies may have features that affect the incentives for countries to cooperate, and the design of selfenforcing-treaties. This paper extends this body of research. Starting from the canonical model of cooperation in reducing emissions, I allow countries to employ a "backstop technology," either in a separate treaty or a combined treaty. For climate change, this backstop technology is industrial "air capture."

The model developed here offers three important insights. First, while economists have overwhelmingly favored cost-effective treaty designs, this paper shows that there are situations in which separate treaties pertaining to different technologies may be superior overall, even though the resulting mitigation is not cost-effective. Second, where a 
combined treaty is to be preferred to separate treaties, the reason is not only that the combined treaty sustains cost-effective abatement. It is that deployment of the backstop technology ratchets up cooperation in ordinary abatement. Finally, if countries persist in failing to reduce emissions substantially, and marginal damages increase as a consequence, use of the backstop technology will eventually be triggered. In an extreme scenario in which the capacity for undertaking air capture is very, very great, and air capture can be undertaken as a single project, marginal damages overall will be limited and equal to the marginal cost of the backstop technology. 
TABLE 3

Simulations: Single Project

\begin{tabular}{|c|c|c|c|c|c|c|}
\hline \multicolumn{2}{|c|}{ Simulation } & I & II & III & IV & V \\
\hline \multirow{4}{*}{ 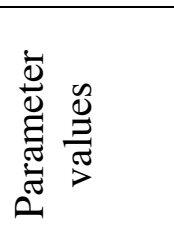 } & $b$ & 1 & 1 & 1 & 1 & 5 \\
\hline & $c$ & 1 & 1 & 1,000 & 1 & 1 \\
\hline & $\gamma$ & 79.5 & 79.5 & 79.5 & 19.5 & 19.5 \\
\hline & $\bar{Z}$ & 1,000 & 750,000 & 1,000 & 1,000 & 1,000 \\
\hline \multirow{4}{*}{ 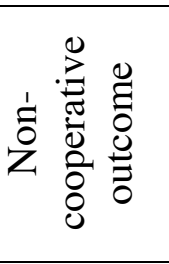 } & $q_{0}$ & 1 & 1 & 0.001 & 1 & 5 \\
\hline & $Q_{0}$ & 100 & 100 & 0.1 & 100 & 500 \\
\hline & $\pi^{o}$ & 99.5 & 99.5 & 0.1 & 99.5 & $2,487.5$ \\
\hline & $\Pi^{o}$ & 9,950 & 9,950 & 9.95 & 9,950 & 248,750 \\
\hline \multirow{5}{*}{ 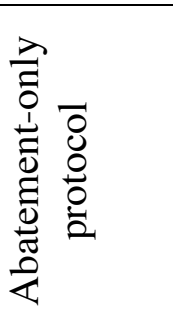 } & $q_{x}^{*}$ & 3 & 3 & 0.003 & 3 & 15 \\
\hline & $Q^{*}$ & 106 & 106 & 0.11 & 106 & 530 \\
\hline & $\pi_{n}^{*}$ & 105.5 & 105.5 & 0.11 & 105.5 & $2,637.5$ \\
\hline & $\pi_{s}^{*}$ & 101.5 & 101.5 & 0.10 & 101.5 & $2,537.5$ \\
\hline & $\Pi_{q}^{*}$ & 10,538 & 10,538 & 10.5 & 10,538 & 263,450 \\
\hline \multirow{5}{*}{ 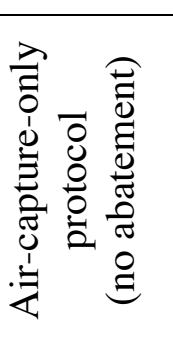 } & $k_{z}^{*}$ & 80 & 80 & 80 & 20 & 4 \\
\hline & $Z^{*}$ & 1,000 & 750,000 & 1,000 & 1,000 & 1,000 \\
\hline & $\pi_{n}^{*}$ & 1,000 & 750,000 & 1,000 & 1,000 & 5,000 \\
\hline & $\pi_{s}^{*}$ & 6.25 & $4,687.5$ & 6.25 & 25 & 125 \\
\hline & $\Pi_{z}^{*}$ & 20,500 & $15,375,000$ & 20,500 & 80,500 & 480,500 \\
\hline \multirow{2}{*}{$\begin{array}{c}\text { Both } \\
\text { protocols }\end{array}$} & $Q^{*}+Z^{*}$ & 1,106 & 750,106 & $1,000.11$ & 1,106 & 1,530 \\
\hline & $\Pi_{q}^{*}+\Pi_{z}^{*}$ & 31,038 & $15,385,538$ & $20,510.5$ & 91,038 & 743,950 \\
\hline \multirow{6}{*}{ 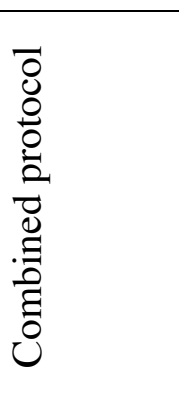 } & $k_{+}^{*}$ & -- & 80 & 80 & 20 & 4 \\
\hline & $q_{s}^{*}$ & -- & 80 & 0.08 & 20 & 20 \\
\hline & $Q_{+}^{*}+Z_{+}^{*}$ & -- & 756,420 & $1,006.42$ & 1,480 & 1,560 \\
\hline & $\pi_{n}^{*}$ & -- & $756,419.5$ & $1,006.42$ & $1,479.5$ & $7,787.5$ \\
\hline & $\pi_{s}^{*}$ & -- & $7,907.5$ & 9.47 & 3,050 & 2,725 \\
\hline & $\Pi_{+}^{*}$ & -- & $15,760,990$ & 20,886 & 124,460 & 758,500 \\
\hline \multirow{5}{*}{ 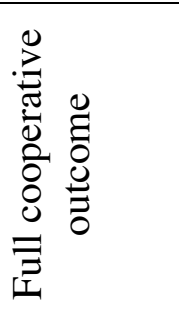 } & $q^{c}$ & 100 & 100 & 0.1 & 100 & 500 \\
\hline & $z^{c}$ & 10 & 7,500 & 10 & 10 & 10 \\
\hline & $Q^{c}+Z^{c}$ & 11,000 & 760,000 & 1,010 & 11,000 & 51,000 \\
\hline & $\pi^{c}$ & 5,205 & 158,750 & 210 & 5,805 & 129,805 \\
\hline & $\Pi^{c}$ & 520,500 & $15,875,000$ & 21,000 & 580,500 & $12,980,500$ \\
\hline
\end{tabular}


TABLE 4

Payoffs to individual countries

\begin{tabular}{|c|c|c|c|c|c|}
\hline Simulation & I & II & III & IV & $\mathbf{V}$ \\
\hline Non-cooperative outcome & 99.5 & 99.5 & 0.1 & 99.5 & $2,487.5$ \\
\hline $\begin{array}{l}\text { Signatory to abatement- } \\
\text { only treaty/Non-signatory } \\
\text { to air-capture-only treaty }\end{array}$ & $1,101.5$ & $750,101.5$ & $1,000.10$ & $1,101.5$ & $7,537.5$ \\
\hline $\begin{array}{l}\text { Non-signatory to } \\
\text { abatement-only } \\
\text { treaty/Signatory to air- } \\
\text { capture-only treaty }\end{array}$ & 111.75 & 4,793 & 6.36 & 130.5 & $2,762.5$ \\
\hline Signatory to both treaties & 107.75 & 4,789 & 6.35 & 126.5 & $2,662.5$ \\
\hline $\begin{array}{l}\text { Non-signatory to both } \\
\text { treaties }\end{array}$ & $1,105.5$ & $750,105.5$ & 800.11 & $1,105.5$ & $7,637.5$ \\
\hline $\begin{array}{l}\text { Expected payoff with } \\
\text { separate treaties }\end{array}$ & 310.38 & $153,855.4$ & 166.3 & 325.4 & $3,734.5$ \\
\hline $\begin{array}{l}\text { Non-signatory to } \\
\text { combined treaty }\end{array}$ & 105.5 & $756,419.5$ & $1,006.42$ & $1,479.5$ & $7,787.5$ \\
\hline $\begin{array}{l}\text { Signatory to combined } \\
\text { treaty }\end{array}$ & 101.5 & $7,907.5$ & 9.47 & 3,050 & 2,725 \\
\hline $\begin{array}{l}\text { Expected payoff with } \\
\text { combined treaty }\end{array}$ & 102.3 & $157,609.9$ & 208.9 & $1,793.6$ & 6,775 \\
\hline Full cooperative outcome & 5,205 & 158,750 & 210 & 5,805 & 129,805 \\
\hline $\begin{array}{l}\text { Who would favor a } \\
\text { combined treaty? }\end{array}$ & No one & $\begin{array}{r}\text { Everyone } \\
\text { ex ante; } \\
\text { signatories } \\
\text { to air- } \\
\text { capture- } \\
\text { only treaty } \\
\text { ex post. }\end{array}$ & $\begin{array}{r}\text { Everyone } \\
\text { ex ante; } \\
\text { signatories } \\
\text { to air- } \\
\text { capture- } \\
\text { only treaty } \\
\text { ex post }\end{array}$ & Everyone & $\begin{array}{r}\text { Everyone } \\
\text { ex ante; } \\
\text { everyone } \\
\text { except } \\
\text { signatories } \\
\text { to one but } \\
\text { not both of } \\
\text { the } \\
\text { individual } \\
\text { treaties ex } \\
\text { post }\end{array}$ \\
\hline
\end{tabular}




\section{REFERENCES}

Barrett, S. (2002). "Consensus Treaties." Journal of Institutional and Theoretical Economics, 158(4): 529-547.

Barrett, S. (2005). Environment and Statecraft: The Strategy of Environmental TreatyMaking, Oxford: Oxford University Press (paperback edition).

Barrett, S. (2006). "Climate Treaties and 'Breakthrough' Technologies." American Economic Review (Papers and Proceedings) 96(2): 22-25.

Barrett, S. (2009). "The Coming Global Climate-Technology Revolution." Journal of Economic Perspectives 23(2): 53-75.

Golombek, R. and M. Hoel (2004). "Unilateral Emission Reductions and Cross-Country Technology Sipllovers.” The B.E. Journals in Economic Analysis \& Policy 4(2).

Heal, G. (1994). "Formation of International Environmental Agreements." In C. Carraro (ed.), Trade, Innovation, Environment. Dordrecht: Kluwer, pp. 301-322.

Hoel, M. and A. de Zeeuw (2009). "Can a Focus on Breakthrough Technologies Improve the Performance of International Environmental Agreements?" mimeo, University of Oslo. 
Pielke, R.A. Jr. (2009). “An Idealized Assessment of the Economics of Air Capture of Carbon Dioxide in Mitigation Policy.” Environmental Science and Policy 12: 216-225.

Sarewitz, Daniel and Richard Nelson (2008). “Three Rules for Technological Fixes.” Nature 456: 871-872. 


\section{CESifo Working Paper Series}

for full list see www.cesifo-group.org/wp

(address: Poschingerstr. 5, 81679 Munich, Germany, office@cesifo.de)

2941 Peter Debaere, Holger Görg and Horst Raff, Greasing the Wheels of International Commerce: How Services Facilitate Firms' International Sourcing, February 2010

2942 Emanuele Forlani, Competition in the Service Sector and the Performances of Manufacturing Firms: Does Liberalization Matter?, February 2010

2943 James M. Malcomson, Do Managers with Limited Liability Take More Risky Decisions? An Information Acquisition Model, February 2010

2944 Florian Englmaier and Steve Leider, Gift Exchange in the Lab - It is not (only) how much you give ..., February 2010

2945 Andrea Bassanini and Giorgio Brunello, Barriers to Entry, Deregulation and Workplace Training: A Theoretical Model with Evidence from Europe, February 2010

2946 Jan-Emmanuel De Neve, James H. Fowler and Bruno S. Frey, Genes, Economics, and Happiness, February 2010

2947 Camille Cornand and Frank Heinemann, Measuring Agents' Reaction to Private and Public Information in Games with Strategic Complementarities, February 2010

2948 Roel Beetsma and Massimo Giuliodori, Discretionary Fiscal Policy: Review and Estimates for the EU, February 2010

2949 Agnieszka Markiewicz, Monetary Policy, Model Uncertainty and Exchange Rate Volatility, February 2010

2950 Hans Dewachter and Leonardo Iania, An Extended Macro-Finance Model with Financial Factors, February 2010

2951 Helmuth Cremer, Philippe De Donder and Pierre Pestieau, Education and Social Mobility, February 2010

2952 Zuzana Brixiová and Balázs Égert, Modeling Institutions, Start-Ups and Productivity during Transition, February 2010

2953 Roland Strausz, The Political Economy of Regulatory Risk, February 2010

2954 Sanjay Jain, Sumon Majumdar and Sharun W. Mukand, Workers without Borders? Culture, Migration and the Political Limits to Globalization, February 2010

2955 Andreas Irmen, Steady-State Growth and the Elasticity of Substitution, February 2010

2956 Bengt-Arne Wickström, The Optimal Babel - An Economic Framework for the Analysis of Dynamic Language Rights, February 2010 
2957 Stefan Bauernschuster and Helmut Rainer, From Politics to the Family: How Sex-Role Attitudes Keep on Diverging in Reunified Germany, February 2010

2958 Patricia Funk and Christina Gathmann, How do Electoral Systems Affect Fiscal Policy? Evidence from State and Local Governments, 1890 to 2005, February 2010

2959 Betsey Stevenson, Beyond the Classroom: Using Title IX to Measure the Return to High School Sports, February 2010

2960 R. Quentin Grafton, Tom Kompas and Ngo Van Long, Biofuels Subsidies and the Green Paradox, February 2010

2961 Oliver Falck, Stephan Heblich, Alfred Lameli and Jens Suedekum, Dialects, Cultural Identity, and Economic Exchange, February 2010

2962 Bård Harstad, The Dynamics of Climate Agreements, February 2010

2963 Frederick van der Ploeg and Cees Withagen, Is There Really a Green Paradox?, February 2010

2964 Ingo Vogelsang, Incentive Regulation, Investments and Technological Change, February 2010

2965 Jan C. van Ours and Lenny Stoeldraijer, Age, Wage and Productivity, February 2010

2966 Michael Hoel, Climate Change and Carbon Tax Expectations, February 2010

2967 Tommaso Nannicini and Roberto Ricciuti, Autocratic Transitions and Growth, February 2010

2968 Sebastian Brauer and Frank Westermann, A Note on the Time Series Measure of Conservatism, February 2010

2969 Wolfram F. Richter, Efficient Education Policy - A Second-Order Elasticity Rule, February 2010

2970 Tomer Blumkin, Yoram Margalioth and Efraim Sadka, Taxing Children: The Redistributive Role of Child Benefits - Revisited, February 2010

2971 Chang Woon Nam and Georg Wamser, Application of Regionally Varying Additionality Degrees in the Practice of EU Cohesion Policy, February 2010

2972 Ali Bayar, Frédéric Dramais, Cristina Mohora, Masudi Opese and Bram Smeets, Modeling Russia for Climate Change Issues, February 2010

2973 Magnus Söderberg, Informal Benchmarks as a Source of Regulatory Threat in Unregulated Utility Sectors, March 2010

2974 Piotr Wdowiński and Marta Malecka, Asymmetry in Volatility: A Comparison of Developed and Transition Stock Markets, March 2010 
2975 Frans van Winden, Michal Krawczyk and Astrid Hopfensitz, Investment, Resolution of Risk, and the Role of Affect, March 2010

2976 Hyun-Ju Koh and Nadine Riedel, Do Governments Tax Agglomeration Rents?, March 2010

2977 Johann K. Brunner and Susanne Pech, Optimum Taxation of Bequests in a Model with Initial Wealth, March 2010

2978 Guglielmo Maria Caporale and Nicola Spagnolo, Stock Market Integration between three CEECs, Russia and the UK, March 2010

2979 Florian Englmaier, Ales Filipi and Ravi Singh, Incentives, Reputation and the Allocation of Authority, March 2010

2980 Konstantinos Angelopoulos, George Economides and Apostolis Philippopoulos, What is the Best Environmental Policy? Taxes, Permits and Rules under Economic and Environmental Uncertainty, March 2010

2981 Frederick van der Ploeg, Rapacious Resource Depletion, Excessive Investment and Insecure Property Rights, March 2010

2982 Wolfram F. Richter and Christoph Braun, Efficient Subsidization of Human Capital Accumulation with Overlapping Generations and Endogenous Growth, March 2010

2983 Francesco Cinnirella, Marc Piopiunik and Joachim Winter, Why Does Height Matter for Educational Attainment? Evidence from German Pre-Teen Children, March 2010

2984 Bernard Van Praag, Well-being Inequality and Reference Groups - An Agenda for New Research, March 2010

2985 Francesca Barion, Raffaele Miniaci, Paolo M. Panteghini and Maria Laura Parisi, Profit Shifting by Debt Financing in Europe, March 2010

2986 Alexander Haupt and Magdalena Stadejek, The Choice of Environmental Policy Instruments: Energy Efficiency and Redistribution, March 2010

2987 John Komlos and Marek Brabec, The Trend of BMI Values among US Adults, March 2010

2988 Emanuele Massetti and Lea Nicita, The Optimal Climate Policy Portfolio when Knowledge Spills across Sectors, March 2010

2989 Helmut Rainer and Thomas Siedler, Family Location and Caregiving Patterns from an International Perspective, March 2010

2990 Toru Kikuchi and Ngo Van Long, A Simple Model of Service Offshoring with Time Zone Differences, March 2010 
2991 Assaf Razin, Efraim Sadka and Benjarong Suwankiri, Migration and the Welfare State: Dynamic Political-Economy Theory, March 2010

2992 Bård Harstad, Buy Coal! Deposit Markets Prevent Carbon Leakage, March 2010

2993 Axel Dreher, Stephan Klasen, James Raymond Vreeland and Eric Werker, The Costs of Favoritism: Is Politically-driven Aid less Effective?, March 2010

2994 Sven Neelsen and Thomas Stratmann, Effects of Prenatal and Early Life Malnutrition: Evidence from the Greek Famine, March 2010

2995 Claude Hillinger and Bernd Süssmuth, The Quantity Theory of Money: An Assessment of its Real Linchpin Prediction, March 2010

2996 Matthew M. Chingos and Martin R. West, Do More Effective Teachers Earn More Outside of the Classroom?, March 2010

2997 Laurence Jacquet and Dirk Van de gaer, A Comparison of Optimal Tax Policies when Compensation or Responsibility Matter, March 2010

2998 Valentina Bosetti, Carlo Carraro, Romain Duval and Massimo Tavoni, What Should we Expect from Innovation? A Model-Based Assessment of the Environmental and Mitigation Cost Implications of Climate-Related R\&D, March 2010

2999 Scott Alan Carson, Nineteenth Century Stature and Family Size: Binding Constraint or Productive Labor Force?, March 2010

3000 Jukka Pirttilä and Ilpo Suoniemi, Public Provision, Commodity Demand and Hours of Work: An Empirical Analysis, March 2010

3001 Bertrand Candelon and Franz C. Palm, Banking and Debt Crises in Europe: The Dangerous Liaisons?, March 2010

3002 Joan Costa-i-Font and Marin Gemmill-Toyama, Does Cost Sharing really Reduce Inappropriate Prescriptions?, March 2010

3003 Scott Barrett, Climate Treaties and Backstop Technologies, March 2010 